\title{
The Role of Mindfulness in the Intimate Relationships and Psychological Wellbeing in Emerging Adulthood
}

\author{
María de Lourdes Rosales-Villacrés ${ }^{1,2}$, Cristián Oyanadel ${ }^{1}{ }^{\mathbb{D}}$, Diana Changotasig-Loja ${ }^{2}$, \\ Ignacio Betancourt-Peters ${ }^{1}$ (D) and Wenceslao Peñate-Castro ${ }^{3, *(D)}$ \\ 1 Departamento de Psicología, Universidad de Concepción, Concepción 4070386, Chile; \\ mariarosales@udec.cl (M.d.L.R.-V.); coyanadel@udec.cl (C.O.); ignacio.beta@gmail.com (I.B.-P.) \\ 2 Facultad de Ciencias Psicológicas, Universidad Central del Ecuador, Quito 170129, Ecuador; \\ dcchangotasig@uce.edu.ec \\ 3 Departamento Psicología Clínica, Psicobiología y Metodología, Facultad de Psicología y Logopedia, \\ Universidad de La Laguna, Campus de Guajara, 38200 La Laguna, Spain \\ * Correspondence: wpenate@ull.edu.es
}

\section{check for} updates

Citation: Rosales-Villacrés, María de Lourdes, Cristián Oyanadel, Diana Changotasig-Loja, Ignacio Betancourt-Peters, and Wenceslao Peñate-Castro. 2021. The Role of Mindfulness in the Intimate Relationships and Psychological Wellbeing in Emerging Adulthood. Social Sciences 10: 259. https:// doi.org/10.3390/socsci10070259

Academic Editor: Michaela Rogers

Received: 29 April 2021

Accepted: 29 June 2021

Published: 8 July 2021

Publisher's Note: MDPI stays neutral with regard to jurisdictional claims in published maps and institutional affiliations.

Copyright: (c) 2021 by the authors. Licensee MDPI, Basel, Switzerland. This article is an open access article distributed under the terms and conditions of the Creative Commons Attribution (CC BY) license (https:// creativecommons.org/licenses/by/ $4.0 /)$.

\begin{abstract}
Little is known about the impact of mindfulness on psychological wellbeing, anxiety, and avoidance in couple relationships. In emerging adulthood, intimate relationships are associated with life satisfaction and changes that can cause psychological maladjustment. This study seeks to determine if dispositional mindfulness acts as a protective variable between psychological wellbeing, anxiety, and avoidance and identify the factors that are protectors. A sample was obtained of 391 young university students between 18 and 25 years old. The Five-Facet Mindfulness Questionnaire, the Ryff Scales of Psychological Wellbeing, and the Experiences in Close Relationships Scale were used. The results show that the highest levels of dispositional mindfulness are associated with greater psychological wellbeing. Dispositional mindfulness cannot act as a protective variable against anxiety and avoidance, and values were non-significant in intimate relationships. It is necessary to continue investigating the most protective facets of mindfulness for both anxiety and avoidance.
\end{abstract}

Keywords: anxiety; avoidance; mindfulness; psychological wellbeing; moderation

\section{Introduction}

Emerging adulthood is a period when individuals between 18 and 25 years old evolve and acquire commitments that structure their adult lives, such as long-term couple relationships, parenting, and stable work (Arnett 2014). A challenge that couples face is the need to be aware of the interdependence between individual aspirations and commitment in longterm couple relationships (Shulman and Connolly 2013; Zimmer-Gembeck et al. 2014). Going from a more casual to a more committed relationship implies learning to know the other more deeply and how to address and resolve disagreements (Tuval-Mashiach and Shulman 2006). Studies have confirmed that adults confront challenges like fear of rejection and abandonment by their partners (anxiety) as well as negative representations of others and the tendency to feel uncomfortable with intimacy (avoidance) (Mikulincer et al. 2002). These two factors are associated with greater levels of psychological anguish (Davila and Bradbury 2001).

Studies have shown that levels of mindfulness are associated with other psychosocial tendencies like empathetic awareness and taking perspectives that strongly predict satisfactory relationships (Kimmes et al. 2020; Quinn-Nilas 2020) and diminish the risk of breakups (Saavedra et al. 2010). The functioning and wellbeing of close ties with others also depend on the willingness and capacity to forgive, sacrifice, and refrain from acting during conflict, as well as accepting the other (Karremans et al. 2017). Consequently, understanding the role of mindfulness can bring order and parsimony to the current state of multiple interventions as well as clarify the connections between the provided treatment and the various results 
(Kazdin 2007), making it necessary to investigate other mechanisms of potential change in mindfulness in other areas of life, considering that little is known about its role in intimate relationships (anxiety and avoidance) and psychological wellbeing.

\subsection{Anxiety and Avoidance in Intimate Relationships}

Hazan and Shaver (1987) conceptualized romantic love as an attachment process similar to the parent-child attachment process. The main propositions about this similarity were as follows. 1. The emotional and behavioral dynamics are governed by the same biological system; for example, adults feel safer when their partner is close, accessible, and receptive, that is, it becomes a safe base from which they can explore the environment around them. 2. In romantic relationships, the main attachment patterns, which can be considered as loving styles (for example: anxious and avoidant), are also observed. 3. Early caregiving experiences act as points of reference and influence, at least in part, for how people behave in their adult romantic relationships. 4. Romantic love implies the interaction of attachment, care, and sex (Fraley and Shaver 2000).

Research has shown that individual differences in adult attachment in the framework of intimate relationships can be understood through two dimensions: anxiety and avoidance (Brennan et al. 1998; Guzmán-González et al. 2019). Anxiety refers to worrying about rejection, the fear of abandonment, and doubt about one's personal worth due to a negative self-image (Mikulincer et al. 2002). In terms of adaptability, anxiety seeks not only to maintain proximity with the attachment figure but also to be watchful of one's surroundings to detect any threat and show anguish to obtain protection. This hyperactivation can be the result of an inconsistent bond or overprotection by the attachment figure (Díaz-Cutraro et al. 2020; Hepper and Carnelley 2012).

Avoidance refers to how individuals avoid closeness and intimacy. The individual has a negative construction of the other, reducing the importance of the relationship and consequently seeking not to depend on him or her. It is an adaptation mechanism to maintain distance from the attachment figure, without showing anguish. It serves to process signs of rejection and represents a tendency towards compulsive self-sufficiency (Hepper and Carnelley 2012). In contrast to the hyperactivation observed with anxiety, systems of attachment deactivate with avoidance, which is the result of rejection or coldness on the part of the attachment figure (Mikulincer et al. 2003). Both anxiety and avoidance can be measured with self-registered scales (Brennan et al. 1998).

Initially, the strategies employed to deal with anxiety and avoidance can be adaptive to access the protection of caregivers. However, this can affect the capacity to build satisfactory intimate relationships in adulthood (Hepper and Carnelley 2012; López et al. 2020; Rocha et al. 2019).

To understand how both anxiety and avoidance can affect the construction of satisfying romantic relationships, we must understand how the bond is built in the couple. Zeifman and Hazan (1997) describe the bond formation stages in adult romantic relationships, indicating that there are several parallels between this process and both mother-child and children's responses to separation and loss. They point out that there are three phases in bond building. (1) The first is preattachment, where there is an initial attraction, flirting, and courtship; individuals evaluate and allow each other to evaluate. Kirkpatrick (1998) adds that they are specifically evaluated with respect to their suitability as a long-term partner and their potential as a father or mother, rather than as a potential attachment figure. (2) The second is attachment-in-the-making, which is where "falling in love" arises, the emotional bond is established, there is a higher level of self-disclosure as a test of commitment, and sexual behavior constitutes a factor that promotes the development of the emotional bond. Furthermore, at this stage, people want their partners to be motivated to stay in a relationship out of love and not out of consideration for an exchange of favors (Kirkpatrick 1998). (3) The third is clear-cut attachment; it is the final phase, and it reflects that the emotional bond and the commitment of the long-term relationship have been established; it includes the functions of safe haven and safe base, some of the characteristics 
of an attachment figure are assumed, such as providing comfort and support in difficult times, and there is mutual trust and a reciprocal alliance. Therefore, both anxiety and avoidance can interfere with this process, reducing the possibility of moving towards the third phase.

\subsection{Mindfulness and Psychological Wellbeing}

In psychology, mindfulness is a capacity inherent to human awareness that allows individuals to deal with events in the moment without judging and accepting them as they emerge in their consciousness (Baer et al. 2004). Mindfulness has been adopted in contemporary psychology as a focus to increase awareness and respond skillfully to mental processes that contribute to mental anguish and maladjusted behavior (Bishop et al. 2004; Chiodelli et al. 2018). Mindfulness has also been defined as a state that is reached by means of a set of techniques that can be acquired through training. Acceptance therapy indicates that all human beings can cultivate a state of mindfulness through the practice of different techniques (Cebolla et al. 2012).

Studies have shown the efficacy of mindfulness-based interventions (MBIs) to improve psychological wellbeing (Baer et al. 2008; Fumero et al. 2020; Hasselberg and Rönnlund 2020). Research has been directed at mediators and mechanisms of attention that favor change (Baer 2009; Baer et al. 2012; Charters 2013). One study has provided evidence that increased attention and self-compassion through mindfulness-based cognitive therapy (MBCT) mediated changes in depressive symptoms after a 15-month follow-up (Kuyken Willem et al. 2010). As well as its effects in psychotherapy, mindfulness can contribute, in general, to improving daily life and adaptive functioning, alleviating suffering, and helping to manage and cope with stress and crisis (Kazdin 2007).

To assess mindfulness as a process, the Five Facets Mindfulness Questionnaire (FFMQ) is available (Baer et al. 2006). The FFMQ serves to identify the most important abilities to predict the reduction of symptoms and increase wellbeing. It also describes the mechanisms through which these beneficial effects are produced (Cebolla et al. 2012; Chien et al. 2020; Pelham et al. 2019). In accordance with its operationalization in five facets, mindfulness is the capacity to (a) observe, (b) describe (ability to put into words what one is experiencing), (c) act with awareness (ability to direct attention to the present moment and one's actions here and now, which is the opposite of acting automatically), (d) not judge (the ability to not judge internal experiences), and (e) not react (the ability to allow and accept the onset and flow of emotional or mental reactions without avoiding them or being overwhelmed by them) (Cash and Whittingham 2010; Meda et al. 2015). A better understanding of the relationship between specific facets of mindfulness and the dimensions of anxiety and avoidance in intimate relationships can improve the development of psychological wellbeing.

\subsection{Research Questions}

The objectives of this study are (1) to identify if determined levels of dispositional mindfulness act as protector factor between psychological wellbeing and anxiety, and avoidance experienced in intimate relationships in emerging adulthood, and to (2) identify the specific facets of mindfulness that have the most significant protector effect between psychological wellbeing and anxiety and intimacy avoidance experienced in intimate relationships in emerging adulthood.

\section{Method}

\subsection{Research Paradigm}

This study is conducted from the perspective of postpositivist critical realism. It assumes an objective reality that can only be understood imperfectly and probabilistically (Guba and Lincoln 1994). This research has a quantitative focus, with a crosscutting correlational and observational design (Hernández et al. 2010). This design was chosen to observe 
and register variables without intervening in the natural course of events. As well, the measurements are unique and register variables quantitatively (Manterola and Otzen 2014).

\subsection{Participants}

The study was conducted in the city of Quito, Ecuador. Participants were undergraduate university students who were recruited by snowball sampling. People were invited to participate voluntarily by advertising the study through social media, visits to higher education institutions, posters, and flyers. The sample was composed of 391 university students between 18 and 25 years old, all residents of the city of Quito, 136 men (mean age $=20.93$ years old), of which 44 were in intimate relationships. There were 255 women (mean age $=21.05$ years old), of which 137 were in intimate relationships. Regarding the marital status of the participants, 377 were single $(96.2 \%)$, five were married (1.3\%), five were divorced $(1.3 \%)$, and four were in a common union $(1 \%)$. Regarding their nationality, 387 were Ecuadorians and 4 were foreigners.

The sampling was done by convenience. Inclusion criteria included being aged between 18 and 25 years, having or having had some type of relationship, and not having any experience in mindfulness or meditation. Exclusion criteria were being followed by a psychologist or psychiatrist for any mental health problems, having recently experienced any important losses, and having a physical condition that may influence the subject's commitment to participating in the research.

Participants who met the inclusion criteria were invited to a face-to-face meeting where the purpose of the study was explained to them. Those who agreed to participate in the study signed informed consent forms, and the data were collected through the pen-and-paper technique, where questionnaires were printed and handed to them so they could complete them. The instruction to answer the couple questionnaire was to think of a current or the most recent relationship.

\subsection{Measures and Procedure}

A sociodemographic data file was designed for this study and the Experiences in Close Relationships, Five-Facet Mindfulness, and Ryff's Psychological Wellbeing questionnaires were used. Given that the questionnaires were not adapted to the Ecuadorian population, confirmatory factorial analysis (CFA) was carried with the sample of this study on the structure of factors described. The chi-square test $\left(X^{2}\right)$, comparative fit index (CFI), TuckerLewis index (TLI), standardized root mean square residual (SRMR), and the root mean squared error of approximation (RMSEA) were considered in valuing the adjustment of the model. CFI and TLI values equal to or higher than 0.90 and SRMR and RMSEA values of less than 0.08 were considered indicators of adequate adjustment (Hu and Bentler 1999).

Sociodemographic data file: A register was prepared to gather sociodemographic information on the participants in the study, such as sex, age, neighborhood of residence, and years of schooling.

Five-Facet Mindfulness Questionnaire (Baer et al. 2006). This questionnaire measures the tendency to have a mindful approach. It is composed of 39 items. A Spanish version that had been adapted to the Chilean population was used (Schmidt and Vinet 2015). The scale was a Likert-type that went from 1 (never or very rarely true) to 5 (very often or always true). The minimum score is 39 points, and the maximum is 195 . The items are grouped into five factors: observation, description, acting with awareness, non-judging, and nonreactivity. The indices obtained in the CFA indicate a good adjustment: $\left(X^{2}=158.95\right.$; $\mathrm{CFI}=0.97$; TLI $=0.95$; SRMR $=0.06$; RMSEA = 0.05). The Cronbach alpha values obtained with this sample were observation-0.79, description-0.84, acting with awareness-0.86, non-judging-0.84, and non-reactivity-0.60.

Experiences in Close Relationships (ECR, Brennan et al. 1998). This scale evaluated two dimensions: anxiety about abandonment (anxiety) and intimacy avoidance (avoidance). Each subscale consisted of 18 items that were measured by a Likert-type scale with 7 points, where 1 was "totally disagree", 4 was "neither agree nor disagree", and 7 was "totally 
agree". A higher score indicates a higher level of anxiety and/or avoidance. The CFA showed a good adjustment of the model to the data $\left(X^{2}=152.019 ; \mathrm{CFI}=0.95 ; \mathrm{TLI}=0.93\right.$; SRMR $=0.07 ;$ RMSEA $=0.07)$. Both avoidance $(\alpha=0.85)$ and anxiety $(\alpha=0.89)$ presented good levels of reliability.

Psychological Wellbeing Scale (PWS, Ryff 1989). This scale evaluates positive attributes of psychological wellbeing. The 39-item scale (Van Dierendonck 2005) was adapted to Spanish and reduced to 29 items (Díaz et al. 2006) and scored by a Likert-type scale that goes from 1 (totally disagree) to 6 (totally disagree). The scale contains six subscales: self-acceptance, positive relationships, autonomy, environmental mastery, personal growth, and purpose in life. These scales are combined to obtain a global score for wellbeing. The values obtained with the CFA show that the model presents a moderately acceptable level of adjustment $\left(X^{2}=115.581 ; \mathrm{CFI}=0.90 ; \mathrm{TLI}=0.89 ; \mathrm{SRMR}=0.07\right.$; RMSEA = 0.08). The global Cronbach alpha score was 0.91 , with 0.80 for self-acceptance, 0.70 for positive relationships, 0.70 for autonomy, 0.60 for environmental mastery, 0.54 for personal growth, and 0.80 for purpose in life. There was a low level of reliability for the dimensions of environmental mastery and personal growth.

\subsection{Data Analysis}

The possible protector effects of the five facets of mindfulness: observation, description, acting with awareness, non-judging, and non-reactivity on the negative aspects (avoidance and anxiety) and dimensions of wellbeing (self-acceptance, positive relationships, purpose in life, etc.) were identified using linear regressions (Hayes 2013) between negative aspects as independent variables and the dimensions of wellbeing as dependent variables, firstly testing if mindfulness moderates the relationship between the negative dimensions and wellbeing, as represented in Figure 1.

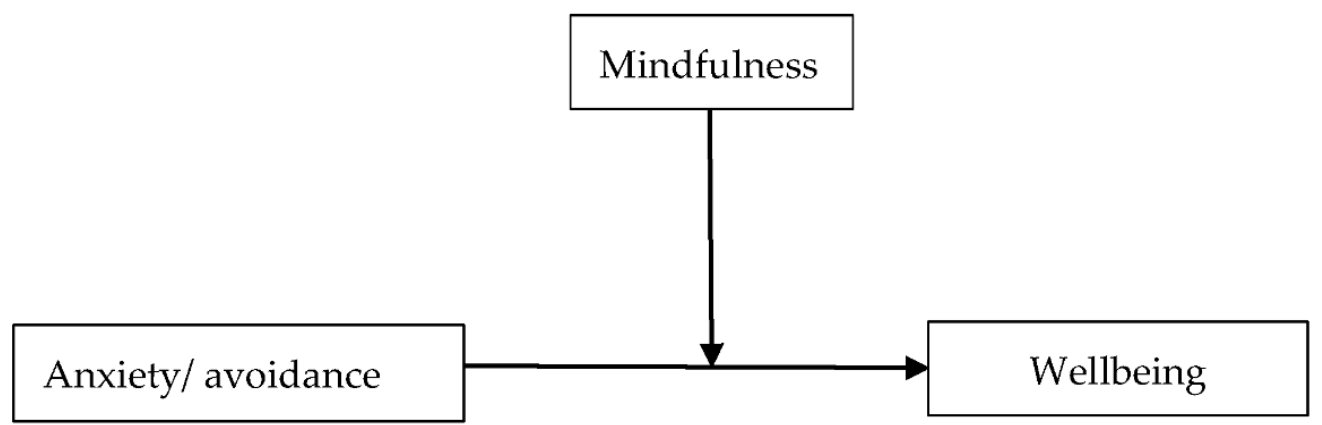

Figure 1. Theoretical model of moderation between anxiety and avoidance in intimate relationships and psychological wellbeing, understanding the role of dispositional mindfulness.

Bootstrap intervals were obtained to verify the significance of the mediating effects at a level of significance of 5\%. PROCESS macro in SPSS software, version 22 (Hayes 2014) was used.

\subsection{Ethical Considerations}

This study was performed in line with the principles of the Declaration of Helsinki. Approval was granted by the Sub-Committee on Ethical Investigation into Human Beings of the Central University of Ecuador (SEISH-UCE), 27 February 2018, Code 0006-FCP-D2017. Informed consent, regarding objectives and data publication, was obtained from all participants included in the study.

\section{Results}

Table 1 shows the results of the descriptive analysis of the study variables in this sample. As shown in the table, the facet of acting with awareness had the highest score and non-judging had the lowest. The highest mean index of psychological wellbeing was autonomy, and the lowest was positive relationships. 
Table 1. Means and standard deviations of the variables of mindfulness, wellbeing, avoidance, and anxiety $(\mathrm{N}=391)$.

\begin{tabular}{cccccc}
\hline & N & Minimum & Maximum & Mean & Standard Deviation \\
\hline Observing & 385 & 11 & 40 & 27.39 & 5.64 \\
\hline Describing & 372 & 8 & 40 & 26.21 & 5.36 \\
\hline Acting with awareness & 378 & 8 & 40 & 27.8 & 5.65 \\
\hline Non-judging & 380 & 8 & 40 & 21.66 & 6.27 \\
\hline Non-reactivity & 380 & 8 & 35 & 21.93 & 4.04 \\
\hline Self-acceptance & 380 & 6 & 36 & 24.55 & 5.27 \\
\hline Positive relationships & 380 & 7 & 36 & 23.74 & 5.60 \\
\hline Autonomy & 383 & 13 & 48 & 32.94 & 6.55 \\
\hline Environmental mastery & 385 & 11 & 36 & 26.05 & 4.83 \\
\hline Personal growth & 381 & 17 & 42 & 32.67 & 4.86 \\
\hline Purpose of life & 386 & 9 & 36 & 27.5 & 5.56 \\
\hline Avoidance & 371 & 18 & 108 & 58.17 & 15.86 \\
\hline Anxiety & 371 & 20 & 118 & 67.12 & 19.25 \\
\hline RYFF Total & 354 & 105 & 267 & 191.09 & 28.86 \\
\hline FFMQ Total & 345 & 79 & 165 & 125.12 & 14.84 \\
\hline
\end{tabular}

Our first hypothesis is that the variables of avoidance and anxiety are related to mindfulness and psychological wellbeing. To determine if this relationship exists, we carried out Pearson-type correlation analyses. Table 2 shows the correlation coefficients and levels of significance.

Table 2. Pearson correlations among avoidance, anxiety, wellbeing, and mindfulness $(\mathrm{N}=391)$.

\begin{tabular}{cccc}
\hline & Avoidance & Anxiety & Wellbeing \\
\hline Anxiety & 0.01 & & \\
Wellbeing & $-0.34^{* *}$ & $-0.42^{* *}$ & $0.59^{* *}$ \\
Mindfulness & $-0.26^{* *}$ & $-0.28^{* *}$ & 0.
\end{tabular}

** $p<0.01$.

The results of the correlation test show that anxiety and avoidance are negatively and significantly related to mindfulness and psychological wellbeing. The correlations are low and moderate, and all are significant, with the exception of avoidance with anxiety. The analysis showed that mindfulness and wellbeing are positively and significantly related, the correlations between them being high, as shown in Table 2 .

Based on the correlations, we hypothesize that mindfulness plays a protector role in avoidance and anxiety experienced in intimate relationships, as well as in psychological wellbeing.

To test whether mindfulness moderates the relationship between anxiety and wellbeing and/or avoidance and wellbeing, each analysis is performed separately according to the model represented in Figure 1, controlling for age and sex.

The results, as seen in Tables 3 and 4, show that there is no moderation, as the interaction effects are not significant in either of the two models, either for the independent variable that corresponds to avoidance $\left(\beta_{\text {interac }}=0.00, p=0.87\right.$ ) or the one that encompasses anxiety $\left(\beta_{\text {interac }}=0.00, p=0.66\right)$. 
Table 3. Model coefficients that consider avoidance as an independent variable.

\begin{tabular}{cccccc}
\hline Model & & $\boldsymbol{\beta}$ & $\mathrm{SE}_{\boldsymbol{\beta}}$ & $\boldsymbol{t}$ & $\boldsymbol{p}$ \\
\hline 1 & Constant & 67.65 & 38.66 & 1.75 & 0.08 \\
& Mindfulness & 1.15 & 0.3 & 3.85 & $<0.001$ \\
& Avoidance & -0.25 & 0.61 & -0.41 & 0.68 \\
& Interaction & 0.00 & 0.00 & -0.17 & 0.87 \\
& Sex & -0.41 & 2.73 I & -0.15 & 0.88 \\
& Age & 0.41 & 0.5 & 0.83 & 0.40 \\
\hline & $\mathrm{F}(3304)=68.11 ; p<0.001 ; \mathrm{R}^{2}=0.39$ \\
\hline
\end{tabular}

Table 4. Model coefficients that consider anxiety as an independent variable.

\begin{tabular}{cccccc}
\hline Model & & $\boldsymbol{\beta}$ & $\mathrm{SE}_{\boldsymbol{\beta}}$ & $\boldsymbol{t}$ & $\boldsymbol{p}$ \\
\hline 2 & Constant & 101.94 & 47.14 & 2.16 & 0.03 \\
& Mindfulness & 0.91 & 0.36 & 2.55 & 0.01 \\
& Anxiety & -0.61 & 0.6 & -1.01 & 0.31 \\
& Interaction & 0.00 & 0.00 & 0.44 & 0.66 \\
& Sex & -0.2 & 2.7 & -0.07 & 0.94 \\
& Age & 0.54 & 0.49 & 1.10 & 0.27 \\
\hline & $\mathrm{F}(3304)=81.36 ; p<0.001 ; \mathrm{R}^{2}=0.41$ \\
\hline
\end{tabular}

Moreover, when reviewing the effect that each negative dimension has on wellbeing, it is seen that it is still significant (Table 5).

Table 5. Effect of avoidance and anxiety on wellbeing for different levels of mindfulness.

\begin{tabular}{ccccccc}
\hline $\begin{array}{c}\text { Mindfulness } \\
\text { Level }\end{array}$ & $\begin{array}{c}\text { Avoidance } \\
\text { Effect }(\boldsymbol{\beta})\end{array}$ & SE & $\boldsymbol{p}$ & $\begin{array}{c}\text { Anxiety } \\
\text { Effect }(\boldsymbol{\beta})\end{array}$ & SE & $\boldsymbol{p}$ \\
\hline Mean -SD & -0.34 & 0.10 & $<0.001$ & -0.39 & 0.09 & $<0.001$ \\
Mean & -0.36 & 0.08 & $<0.001$ & -0.36 & 0.07 & $<0.001$ \\
Mean + SD & -0.37 & 0.12 & $<0.001$ & -0.33 & 0.10 & $<0.001$ \\
\hline
\end{tabular}

However, to examine in more detail the influence that mindfulness skills have on the relationship between negative dimensions and wellbeing, subjects were categorized into those with low and high levels of mindfulness; this was determined by dividing the observed range of values of the variable into two groups and then categorizing each subject depending on whether their mindfulness score was within the lowest or highest half of the values. It was first checked whether, in the presence of negative dimensions, the mindfulness category is significant for predicting wellbeing, using a regression model that includes these three variables and controlling for sex and age variables. According to this model, which results can be seen in Table 6 , the variables avoidance $(\beta=-0.487, p<0.001)$, anxiety $(\beta=-0.461, p<0.001)$, and categorized level of mindfulness $(\beta=20.835, p<0.001)$ were significant.

Hence, to better explore the differences in the influence that avoidance and anxiety have on wellbeing, regression models were applied for each level of mindfulness group separately (high and low levels). The difference between this approach and the one of moderation is mainly to consider regression models where both variables (anxiety and avoidance) are covered jointly and to explore how they are related to wellbeing in both groups. The results of these models can be seen in Tables 7 and 8 . 
Table 6. Model with avoidance, anxiety, mindfulness category, and control variables.

\begin{tabular}{cccccc}
\hline Model & & $\mathbf{B}$ & $\mathbf{S E}_{\boldsymbol{\beta}}$ & $\boldsymbol{t}$ & $\boldsymbol{p}$ \\
\hline 3 & Constant & 229.63 & 13.80 & 16.46 & $<0.001$ \\
& Avoidance & -0.487 & 0.08 & -5.81 & $<0.001$ \\
& Anxiety & -0.461 & 0.07 & -6.31 & $<0.001$ \\
& Mindfulness Level & 20.835 & 2.90 & 7.17 & $<0.001$ \\
& Age & 0.694 & 0.51 & 1.37 & 0.170 \\
& Sex & -3.630 & 2.75 & -1.32 & 0.188 \\
\hline & $\mathrm{F}(5295)=37.46 ;$ & $<0.001 ; \mathrm{R}^{2}=0.62 ; \mathrm{R}^{2}$ adjust $=0.38$ \\
\hline
\end{tabular}

Table 7. Model for subgroup cases with low level of mindfulness.

\begin{tabular}{cccccc}
\hline Model & & $\boldsymbol{\beta}$ & $\mathrm{SE}_{\boldsymbol{\beta}}$ & $\boldsymbol{t}$ & $\boldsymbol{p}$ \\
\hline 4a & Constant & 254.76 & 11.52 & 22.11 & $<0.001$ \\
& Avoidance & -0.513 & 0.12 & -4.29 & $<0.001$ \\
& Anxiety & -0.659 & 0.10 & -6.42 & $<0.001$ \\
\hline & $\mathrm{F}(2117)=26.86 ; p<0.001 ; \mathrm{R}^{2}=0.315 ; \mathrm{R}_{\text {adjust }}^{2}=0.303$ \\
\hline
\end{tabular}

Table 8. Model for subgroup cases with high level of mindfulness.

\begin{tabular}{cccccc}
\hline Model & & $\boldsymbol{\beta}$ & $\mathrm{SE}_{\boldsymbol{\beta}}$ & $\boldsymbol{t}$ & $\boldsymbol{p}$ \\
\hline $\mathrm{4b}$ & Constant & 247.43 & 9.60 & 25.77 & $<0.001$ \\
& Avoidance & -0.465 & 0.114 & -4.07 & $<0.001$ \\
& Anxiety & -0.295 & 0.101 & -2.92 & $<0.001$ \\
\hline & $\mathrm{F}(2179)=11.64 ; p<0.001 ; \mathrm{R}^{2}=0.115 ; \mathrm{R}_{\text {adjust }}^{2}=0.105$ & \\
\hline
\end{tabular}

It is seen that in both models, both avoidance and anxiety are significant in predicting the level of wellbeing $(p<0.001)$; however, by comparing the magnitude of the relationship between each negative dimension and wellbeing (expressed as sensitivity through beta coefficients), it is seen that this is descriptively lower for the group of subjects with high levels of mindfulness, both for avoidance and anxiety. This would suggest that although both dimensions are still significant for wellbeing, their impact would be lower in subjects with high levels of mindfulness. This is also suggested by the correlations between anxiety and wellbeing, obtained by each group. While the correlation between avoidance and wellbeing is almost the same in both groups $(r=-0.27, p<0.001)$, on the other hand, its magnitude is higher between anxiety and wellbeing in subjects with lower mindfulness levels $(\mathrm{r}=-0.46, p<0.001)$ than in subjects with higher mindfulness levels $(\mathrm{r}=-0.2$, $p<0.001)$.

\section{Discussion}

This study examined the importance of mindfulness as a protective factor in intimate relationships that experience anxiety or avoidance and as a factor that promotes psychological wellbeing in a nonclinical sample composed of emerging adults.

Although mindfulness does not moderate the relationship that anxiety and avoidance have with wellbeing, the fact of observing this descriptive difference in the beta coefficients and correlations invites us to continue carrying out research in this regard. This analysis can be replicated in other samples, for example, with subjects with a certain experience in the practice of meditation, to see if the fact of having trained mindfulness skills (dimensions) ends up showing a different relationship between negative dimensions and wellbeing compared to subjects who have no experience of this type of practice.

The results of this study agree with others in which mindfulness is associated with higher levels of happiness and less stress in relationships and effectiveness in coping with stress (Carson et al. 2004), as well as higher levels of satisfaction with relationships, 
greater ability to respond constructively to relationship stress, positive change in the perception of the relationship, and higher quality of communication during interactions (Barnes et al. 2007; Quinn-Nilas 2020).

Insecure attachments (anxiety or avoidance) are associated with hostility, lower quality, and less stability in relationships, high levels of depression and anxiety, unhealthy behavior, less productive career choices, and lower performance in work (Shaver and Mikulincer 2007). Insecure attachment is operationally defined by high scores in two dimensions: anxiety and avoidance. Anxiety is characterized by fear of rejection and the absence of love, anger because of the threat of separation, and a need for approval and love. Avoidance is characterized by discomfort with closeness and interdependence, preference for emotional distancing, distrust in the relationship, and extreme self-sufficiency (Shaver et al. 2007). Consequently, influencing these facets contributes to reducing levels of anxiety and avoidance and promotes more satisfying couple relationships and psychological wellbeing.

Although it was not possible to identify which of the mindfulness facets has the most impact as a protective factor, there are studies in which relevant information has been found in this regard. For example, it was found that in situations of infidelity, lower levels of the facets acting with awareness and non-judging the internal experience were related to higher levels of unforgiveness (Johns et al. 2015).

Another study found that the facet of observation in relation to psychological adjustment varies according to the level of meditation that is practiced (Baer et al. 2008), which is associated negatively with psychological health (Bodenlos et al. 2015). This suggests that observing is more associated with cognitive or emotional fusion behavior if not accompanied by description, which implies distancing one's self and forming a perspective of the situation. It has also been found that, effectively, the subscales of non-judging and non-reactivity have a stronger mediating effect among individuals who participate in mindfulness-based programs and perceived stress, depressive symptoms and positive states (Lönnberg et al. 2020), as well as the symptomology of individuals diagnosed with borderline personality disorder (Mitchell et al. 2019) and that were significantly and positively associated with emotional wellbeing (Bodenlos et al. 2015).

At a theoretical level, deepening the study of avoidance and anxiety in intimate relationships broadens our understanding of the Theory of Attachment and allows the interpretation of attachment as a complex and dynamic process, as well as the heterogeneity in experiences of attachment (Galán 2016). Mindfulness can be a mechanism of change to redefine our understanding of relationships with caregivers during childhood and act with awareness here and now to favor psychological wellbeing.

As limitations of our study, we had to use only self-registered measurements, which could be combined with more objective methods such as physiological measurements and neurobiological and behavioral assessments to provide a multimodal system of evaluation of the levels of mindfulness (Chien et al. 2020). The transversal design does not allow for determining causal relationships among the variables. As the sample was composed of nonclinical subjects, limited generalizations can be made of the findings. Another limitation of this study is that other latent variables were not considered for analysis. There are several confounding factors such as relationship status, socio-economic status, health behaviors (e.g., alcohol consumption), and health status, including morbidities. They were not considered necessary for the model we were trying to test; however, we consider them relevant for future analysis. Future studies could use longitudinal designs that consider the practice of mindfulness in couple relationships to determine if the conclusions of this study are supported.

\section{Conclusions and Implications}

Future studies should consider other factors of intimate relationships besides anxiety and avoidance, factors that improve conjugal intimacy and favor the construction of more satisfying, stable, and functional relationships (Kamali et al. 2020). In addition, it would also be interesting to evaluate whether mindfulness can be a key component for intervention in 
codependent relationships (Aristizábal 2020) as well as for reducing violent relationships (Di Napoli et al. 2019; World Health Organization 2012).

According to these findings, evaluating mindfulness in relationships allows for investigating its role in intimate relationships and developing and refining training programs to develop more conscious relationships and to train therapists to optimize therapeutic change with more strategies to trigger processes of critical change, identify facets on which efficacy of a determined treatment can depend, and finally understand the processes through which treatment operates (Chien et al. 2020; Kazdin 2007).

Deepening our knowledge of possible active principles of mindfulness would allow us to identify practices that increase the capacity for mindfulness and determine how these practices affect the physical and psychological wellbeing of individuals (Baer 2009; Grossman 2019) and their relationships.

To arrive at more definitive conclusions about the facets of mindfulness and their relationship to the variables of anxiety and avoidance and those of psychological wellbeing requires replications of this type of study to confirm or deny the findings. This requires using samples with meditators from the general community, including same-sex partners and couples in which there have been violent interactions.

Author Contributions: Contributed to the conception and design, M.d.L.R.-V., C.O. and W.P.-C.; methodology, M.d.L.R.-V., C.O. and W.P.-C.; software, I.B.-P.; validation, M.d.L.R.-V. and D.C.-L.; formal analysis, I.B.-P.; investigation, M.d.L.R.-V., C.O., D.C.-L. and W.P.-C.; resources, M.d.L.R.V., C.O. and W.P.-C.; writing-original draft preparation, M.d.L.R.-V. and I.B.-P.; writing—review and editing, M.d.L.R.-V., C.O., D.C.-L., I.B.-P. and W.P.-C.; supervision, C.O. and W.P.-C.; project administration, M.d.L.R.-V., C.O. and W.P.-C.; funding acquisition, M.d.L.R.-V., C.O. and W.P.-C. All authors have read and agreed to the published version of the manuscript.

Funding: The authors declare having received financial support from the Doctoral Program in Psychology of the Faculty of Social Sciences of the Universidad de Concepción for the translation; this study was funded by the Universidad Central del Ecuador as part of the doctoral studies scholarship of the first author; in addition, it received funding from the National Agency for Research and Development (ANID)/International Cooperation Program/Projects PAI80160045 \& MEC80180087 of the Chilean Ministry of Science, Technology, Knowledge and Innovation.

Institutional Review Board Statement: This study was performed in line with the principles of the Declaration of Helsinki. Approval was granted by the Subcommittee for Ethical Investigation on Human Beings of the Universidad Central del Ecuador (SEISH-UCE), 27 February 2018, Code 0006-FCP-D-2017.

Informed Consent Statement: Informed consent was obtained from all individual participants included in the study.

Data Availability Statement: Data in (Rosales-Villacrés 2021).

Conflicts of Interest: The authors declared no conflicts of interest with respect to the research, authorship, and/or publication of this article.

\section{References}

Aristizábal, Luz Adriana. 2020. Codependency in the Relations of Couples of Imprisoned Women. Social Science 9: 189. [CrossRef] Arnett, Jeffrey Jensen. 2014. Emerging Adulthood: The Winding Road from the Late Teens through the Twenties, 2nd ed. New York: Oxford Scholarship Online. [CrossRef]

Baer, Ruth A. 2009. Self-focused attention and mechanisms of change in mindfulness-based treatment. Cognitive Behaviour Therapy 38: 15-20. [CrossRef]

Baer, Ruth A., Gregory T. Smith, and Kristin B. Allen. 2004. Assessment of Mindfulness by Self-Report The Kentucky Inventory of Mindfulness Skills. Assessment 11: 191-206. [CrossRef] [PubMed]

Baer, Ruth A., Gregory T. Smith, Jaclyn Hopkins, Jennifer Krietemeyer, and Leslie Toney. 2006. Using self-report assessment methods to explore facets of mindfulness. Assessment 13: 27-45. [CrossRef] [PubMed]

Baer, Ruth A., Gregory T. Smith, Emily Lykins, Daniel Button, Jennifer Krietemeyer, Shannon Sauer, Erin Walsh, Danielle Duggan, and J. Mark G. Williams. 2008. Construct Validity of the Five Facet Mindfulness Questionnaire in Meditating and Nonmeditating Samples. Assessment 15: 329-42. [CrossRef] 
Baer, Ruth A., Emily L. B. Lykins, and Jessica R. Peters. 2012. Mindfulness and self-compassion as predictors of psychological wellbeing in long-term meditators and matched nonmeditators. Journal of Positive Psychology 7: 230-38. [CrossRef]

Barnes, Sean, Kirk W. Brown, Elizabeth Krusemark, W. Keith Campbell, and Ronald D. Rogge. 2007. The role of mindfulness in romantic relationship satisfaction and responses to relationship stress. Journal of Marital and Family Therapy 33: 482-500. [CrossRef]

Bishop, Scott, Mark Lau, Shauna Shapiro, Linda Carlson, Nicole D. Anderson, James Carmody, Zindel V. Segal, susan Abbey, Michael Speca, Drew Velting, and et al. 2004. Mindfulness: A Proposed Operational Definition. Clinical Psychology: Science and Practice 11: 230-41. [CrossRef]

Bodenlos, Jamie, Stephanie Y Wells, Marleah Noonan, and Aubreyanne Mayrsohn. 2015. Facets of Dispositional Mindfulness and Health among College Students. The Joournal of Alternative and Complementary Medicine 21: 1-8. [CrossRef]

Brennan, Kelly, Catherine Clark, and Phillip Shaver. 1998. Selfreport measurement of adult attachment: An integrative overview. In Attachment Theory and Close Relationships. Edited by Rholes W. S. New York: Guilford Press, pp. 46-76.

Carson, James, Kimberly Carson, Karen Gil, and Donald Baucom. 2004. Mindfulness-based relationship enhancement. Behavior Therapy 35: 471-94. [CrossRef]

Cash, Morgan, and Koa Whittingham. 2010. What Facets of Mindfulness Contribute to Psychological Well-being and Depressive, Anxious, and Stress-related Symptomatology? Mindfulness 1: 177-82. [CrossRef]

Cebolla, Ausiás, Azucena García-Palacios, Joaquim Soler, Verónica Guillen, and Cristina Botella. 2012. Psychometric properties of the Spanish validation of the Five Facets of Mindfulness Questionnaire (FFMQ). The European Journal of Psychiatry 26: 118-26. [CrossRef]

Charters, Wendy L. 2013. The Essence and Mechanisms of Mindfulness in Therapeutic Context. Canadian Journal of Counselling and Psychotherapy 47: 342-60.

Chien, Wai T., KaMing Chow, Yuen Yu Chong, Daniel Bressington, Kai Chow Choi, and Carmen Wing H. Chan. 2020. The Role of Five Facets of Mindfulness in a Mindfulness-Based Psychoeducation Intervention for People With Recent-Onset Psychosis on Mental and Psychosocial Health Outcomes. Frontiers in Psychiatry 11: 177. [CrossRef] [PubMed]

Chiodelli, Roberto, Luana T. N. Mello, Saul N. Jesus, and Ilana Andretta. 2018. Effects of a brief mindfulness-based intervention on emotional regulation and levels of mindfulness in senior students. Psicologia: Reflexão e Crítica 31: 21. [CrossRef] [PubMed]

Davila, Joanne, and Thomas N. Bradbury. 2001. Attachment insecurity and the distinction between unhappy spouses who do not divorce. Journal of Family Psychology 15. [CrossRef]

Di Napoli, Immacolata, Fortuna Procentese, Stefania Carnevale, Ciro Esposito, and Caterina Arcidiacono. 2019. Ending intimate partner violence (Ipv) and locating men at stake: An ecological approach. International Journal of Environmental Research and Public Health 16: 1652. [CrossRef] [PubMed]

Díaz, Darío, Raquel Rodríguez-Carvajal, Amalio Blanco, Bernardo Moreno-Jiménez, Ismael Gallardo, Carmen Valle, and Dirk Van Dierendonck. 2006. Adaptación española de las escalas de bienestar psicológico de Ryff. Psicothema 18: 572-77.

Díaz-Cutraro, Luciana, Eugenia Amarfil, and Susana Ochoa. 2020. The Relationship Between Attachment and Social Cognition in Psychosis: A Systematic Review. Psicosomática Y Psiquiatría 12: 17-29.

Fraley, R. Chris, and Phillip R. Shaver. 2000. Adult romantic attachment: Theoretical developments, emerging controversies, and unanswered questions. Review of General Psychology 4: 132-54. [CrossRef]

Fumero, Ascensión, Wenceslao Peñate, Cristián Oyanadel, and Bárbara Porter. 2020. The Effectiveness of Mindfulness-Based Interventions on Anxiety Disorders. A Systematic Meta-Review. Investigation in Health, Psychology and Education 10: 52. [CrossRef]

Galán, Antonio. 2016. La teoría del apego: Confusiones, delimitaciones conceptuales y desafío. Revista de La Asociación Española de Neuropsiquiatría 36: 45-61. [CrossRef]

Grossman, Paul. 2019. On the porosity of subject and object in 'mindfulness' scientific study: Challenges to 'scientific' construction, operationalization and measurement of mindfulness. Current Opinion in Psychology 28: 102-07. [CrossRef] [PubMed]

Guba, Egon, and Yvonna Lincoln. 1994. Paradigmas en competencia en la investigación cualitativa. In Handbook of Qualitative Research. Edited by Norman Denzin. London: Sage, pp. 105-17. Available online: http://sgpwe.izt.uam.mx/pages/egt/Cursos/ MetodoLicIII/7_Guba_Lincoln_Paradigmas.pdf (accessed on 27 April 2021).

Guzmán-González, Monica, Sebastián Almonte, Diego Durán, Gina Maechel, and Ariel Rivero. 2019. Apego adulto y perdón a la expareja en el contexto del divorcio-separación. Salud and Sociedad 10: 272-83. [CrossRef]

Hasselberg, Aurora, and Michael Rönnlund. 2020. Cultivating self-kindness and attention to the present moment in the young: A pilot-study of a two-week internet-delivered mindfulness and self-compassion program. Cogent Psychology 7: 1769807. [CrossRef]

Hayes, Andrew. 2013. Introduction. In Introduction to Mediation, Moderation, and Conditional Process Analysis: A Regression-Based Approach. New York: The Guilford Press, pp. 3-22. [CrossRef]

Hayes, Andrew. 2014. Supplementary PROCESS Documentation. In Introduction to Mediation, Moderation, and Conditional Process Analysis. New York: The Guilford Press, pp. 12-14. Available online: https:/ / www.afhayes.com/introduction-to-mediationmoderation-and-conditional-process-analysis.html (accessed on 27 April 2021).

Hazan, Cindy, and Phillip Shaver. 1987. Romantic love conceptualized as an attachment process. Journal of Personality and Social Psychology 52: 511-24. [CrossRef]

Hepper, Erica G., and Katherine B. Carnelley. 2012. Attachment and romantic relationships: The role of models of self and other. In The Psychology of Love. Edited by I. M. Paludi. Santa Barbara: Praeger, vol. 1, pp. 133-54. 
Hernández, Roberto, Carlos Fernández, and María del Pilar Baptista. 2010. Definición del alcance de la investigación a realizar: Exploratoria, descriptiva, correlacional o explicativa. In Metodología de la Investigación. México: Mc Graw Hill, pp. 76-88.

$\mathrm{Hu}, \mathrm{Li}$ Tze, and Peter M. Bentler. 1999. Cutoff criteria for fit indexes in covariance structure analysis: Conventional criteria versus new alternatives. Structural Equation Modeling 6: 1-55. [CrossRef]

Johns, Keri N., Elizabeth S. Allen, and Kristina Coop Gordon. 2015. The Relationship between Mindfulness and Forgiveness of Infidelity. Mindfulness 6: 1462-71. [CrossRef]

Kamali, Zoleikha, Negah Allahyar, Shahla Ostovar, Syed Mohamed Shafeq Alhabshi bin Syed Mansor Alhabshi, and Mark D. Griffiths. 2020. Factors that influence marital intimacy: A qualitative analysis of iranian married couples. Cogent Psychology 7. [CrossRef]

Karremans, Johan C., Melanie P. J. Schellekens, and Gesa Kappen. 2017. Bridging the Sciences of Mindfulness and Romantic Relationships: A Theoretical Model and Research Agenda. Personality and Social Psychology Review 21: 29-49. [CrossRef]

Kazdin, Alan E. 2007. Mediators and Mechanisms of Change in Psychotherapy. Annual Review of Clinical Psychology 3: 1-27. [CrossRef] [PubMed]

Kimmes, Jonathan G., Matthew E. Jaurequi, Kathryn Roberts, Victor W. Harris, and Frank D. Fincham. 2020. An examination of the association between relationship mindfulness and psychological and relational well-being in commited couples. Journal of Marital and Family Therapy 46: 30-41. [CrossRef]

Kirkpatrick, Lee A. 1998. Evolution, Pair-Bonding, and Reproductive Strategies: A Reconceptualization of Adult Attachment. In Attachment Theory and Close Relationships. Edited by Jeffry A. Simpson and W. Steven Rholes. New York: The Guilford Press, pp. 353-93.

Kuyken Willem, Ed Watkins, Emily Holden, Kat White, Rod S. Taylor, Sarah Byford, Alison Evans, Sholto Radford, John D. Teasdale, and Tim Dalgleish. 2010. How does mindfulness-based cognitive therapy work? Behav Res Ther. 48: 1105-12. [CrossRef]

Lönnberg, Gunilla, Wibke Jonas, Eva Unternaehrer, Richard Bränström, Eva Nissen, and Maria Niemi. 2020. Effects of a mindfulness based childbirth and parenting program on pregnant women' s perceived stress and risk of perinatal depression-Results from a randomized controlled trial. Journal of Affective Disorders 262: 133-42. [CrossRef]

López, Adis A., Hernández Eniuska, and Gretter A. Rey. 2020. Loving Attachment of Young University Students in Havana. Universidad de La Habana 290: 138-57. Available online: http:/ / scielo.sld.cu/scielo.php?script=sci_arttextandpid=S0253-9276202000020013 8andlng=esandtlng=en (accessed on 27 April 2021).

Manterola, Carlos, and Tamara Otzen. 2014. Estudios observacionales. Los diseños utilizados con mayor frecuencia en investigación clínica. International Journal of Morphology 32: 634-45. [CrossRef]

Meda, Rosa, Marta Herrero, Luis M. Blanco-Donoso, Bernardo Moreno-Jiménez, and Andrés Palomera. 2015. Propiedades psicométricas del "cuestionario de cinco facetas de la conciencia plena" (five facet mindfulness questionnaire, (FFMQ-M) en México. Behavioral Psychology/Psicologia Conductual 23: 467-87.

Mikulincer, M., Omri Gillath, and Phillip R. Shaver. 2002. Activation of the attachment system in adulthood: Threat-related primes increase the accessibility of mental representations of attachment figures. Journal of Personality and Social Psychology 83: 881-95. [CrossRef]

Mikulincer, Mario, Phillip R. Shaver, and Dana Pereg. 2003. Attachment Theory and Affect Regulation: The Dynamics, Development, and Cognitive Consequences of Attachment-Related Strategies. Motivation and Emotion 27: 77-102. [CrossRef]

Mitchell, Roberta, Rachel Roberts, Dianna Bartsch, and Thomas Sullivan. 2019. Changes in mindfulness facets in a dialectical behaviour therapy skills training group program for borderline personality disorder. Journal of Clinical Psychology 75: 958-69. [CrossRef] [PubMed]

Pelham, William E., David P. Mackinnon, Oscar Gonzalez, Stephen A. Metcalf, Cady L. Whicker, Katie Witkiewitz, and Lisa A. Marsch. 2019. Evaluating the Factor Structure of Each Facet of the Five Facet Mindfulness Questionnaire. Mindfulness 10: $2629-46$. [CrossRef]

Quinn-Nilas, Christopher. 2020. Self-Reported Trait Mindfulness and Couples' Relationship Satisfaction: A Meta-Analysis. Mindfulness 11: 835-48. [CrossRef]

Rocha, Brenda L., Jaqueline Umbarila, Magda Meza, and Fabián A. Riveros. 2019. Estilos de apego parental y dependencia emocional en las relaciones románticas de una muestra de jóvenes universitarios en Colombia. Diversitas 15: 285-99. [CrossRef]

Rosales-Villacrés, María de Lourdes. 2021. Database: The mediating role of mindfulness in the relationships of couples and psychological wellbeing in emerging adulthood. Mendeley Data V2. [CrossRef]

Ryff, Carol D. 1989. Happiness Is Everything, or Is It ? Explorations on the Meaning of Psychological Well-Being. Journal of Personality and Social Psychology 57: 1069-81. [CrossRef]

Saavedra, Maria C., Karina E. Chapman, and Ronald D. Rogge. 2010. Clarifying Links between Attachment and Relationship Quality: Hostile Conflict and Mindfulness as Moderators. Journal of Family Psychology 24: 380-90. [CrossRef] [PubMed]

Schmidt, Carlos, and Eugenia V. Vinet. 2015. Atención Plena: Validación del Five Facet Mindfulness Questionnaire (FFMQ) en estudiantes Universitarios Chilenos. Terapia Psicológica 33: 93-102. [CrossRef]

Shaver, Phillip R., and Mario Mikulincer. 2007. Adult Attachment Strategies and the Regulation of Emotion. In Handbook of Emotion Regulation. Edited by James J. Gross. New York: Guilford Press, pp. 446-65.

Shaver, Phillip R., Shiri Lavy, Clifford D. Saron, and Mario Mikulincer. 2007. Social foundations of the capacity for mindfulness: An attachment perspective. Psychological Inquiry 18: 264-71. [CrossRef] 
Shulman, Shmuel, and Jennifer Connolly. 2013. The Challenge of Romantic Relationships in Emerging Adulthood: Reconceptualization of the Field. Emerging Adulthood 1: 27-39. [CrossRef]

Tuval-Mashiach, Rivka, and Shmuel Shulman. 2006. Resolution of disagreements between romantic partners, among adolescents, and young adults: Qualitative analysis of interaction discourses. Journal of Research on Adolescence 16: 561-88. [CrossRef]

Van Dierendonck, Dirk. 2005. The construct validity of Ryff's Scales of Psychological Well-being and its extension with spiritual well-being. Personality and Individual Differences 36: 629-43. [CrossRef]

World Health Organization, and Pan American Health Organization. 2012. Understanding and Addressing Violence against Women: Intimate Partner Violence. Geneva: World Health Organization, pp. 491-98. [CrossRef]

Zeifman, Debra, and Cindy Hazan. 1997. Attachment: The Bond in Pair-Bonds. In Evolutionary Social Psychology. Edited by Jeffry A. Simpson and Douglas T. Kenrick. Lawrence: Associates Inc., pp. 237-63.

Zimmer-Gembeck, Melanie J., Vanessa Arnhold, and Jennifer Connolly. 2014. Intercorrelations of intimacy and identity dating goals with relationship behaviors and satisfaction among young heterosexual couples. Social Sciences 3: 44-59. [CrossRef] 